\title{
Bullying Among High School Students and Their Relationship with Diligence at School
}

\author{
Laid Fekih \\ Department of Psychology, Faculty of Social Sciences, University of Aboubekr Belkaid, Tlemcen, Algeria
}

\section{Email address:}

fekih_laid@yahoo.fr

\section{To cite this article:}

Laid Fekih. Bullying Among High School Students and Their Relationship with Diligence at School. International Journal of Education, Culture and Society. Vol. 2, No. 4, 2017, pp. 114-119. doi: 10.11648/j.ijecs.20170204.12

Received: August 16, 2017; Accepted: August 23, 2017; Published: September 8, 2017

\begin{abstract}
The present research aims to estimate and compare the prevalence of bullying among high school students, and their relationship with diligence at school. To achieve the purpose of this research was chosen intended sample selected from high school containing 900 students in Tlemcen -Algeria-, including 406 boys and 496 girls aged between 15 and 17 years old, were sampled on the random basis. The results indicated thatthe prevalence of bullying inside schools within the limits of $10 \%$ and $16 \%$. The boy's students in high schools are more violent than girls. The forms of bullying widespread among students are psychological forms as name-calling, humiliation or offensive teasing and being ignored or excluded from a circle of friends. In addition, bullying is related negatively to diligent at school $(r=-0.43, p<0.001)$. Students who were bullied become less efficient, they get low marks, have difficulties in concentration and attention, do not participate in school activities, and absent from school.
\end{abstract}

Keywords: Bullying, Diligence in School, High School Students

\section{Background of Study}

Bullying is unwanted, aggressive behavior among school aged children that involves a real or perceived power imbalance. The behavior is repeated, or has the potential to be repeated, over time. Bullying includes actions such as making threats, spreading rumors, attacking someone physically or verbally, and excluding someone from a group on purpose [1]. Bullying contains the following elements [2]:

a. The person doing the bullying has more power than the one being victimized.

b. Bullying is often organized, systematic, and hidden.

c. Bullying is sometimes opportunistic, and hidden.

d. It usually occurs over a period of time, although those who regularly bully may also carry out one- off incidents.

e. A victim of bullying can be hurt physically, emotionally, or psychologically.

f. All acts of bullying have an emotional or psychological dimension.

Finally bullying was defined as including: physical, verbal, or psychological attack or intimidation that is intended to cause fear, distress, or harm to the victim; and an imbalance of power, with the more powerful child oppressing less powerful ones.

The first data on the prevalence of bullying in schools was collected in Norway by Dan Olweus [3], he Confirms that School bullying is an negative acts set deliberately by a pupil or more to harm another student frequently and all the time, such as: threat, reprimand and insults, or can be physical friction as hitting, pushing, kicking, or even without use of words or physical exposure such as facial grimacing or inappropriate signals, in order to marginalized it or refused to respond to his desire. According to Olweus we talk about bullying, in the case of an imbalance of power, or in the case of difficulty of self-defense, but when a dispute between two students arises almost equal in terms of physical strength, it is not called bullying. Therefore, Juvonen and Graham [4] define Bullying that is the use of force, threat, or coercion to abuse, intimidate or aggressively dominate others. The behavior is often repeated and habitual. One essential prerequisite is the perception, by the bully or by others, of an imbalance of social or physical power, which distinguishes bullying from conflict. Behaviors used to assert such domination can include verbal harassment or threat, physical assault or coercion, and such acts may be directed repeatedly towards particular targets. 
Bullying began to spread in our schools increasingly, and enough access to global statistics on this phenomenon to determine the seriousness. In the United States where bullying is most presence of violence, studies indicate that eight high school students absent one day a week at least because of the fear of bullying. Also a survey of 2,088 Norwegian eighth-graders found that both bullies and victims had higher scores on measures of suicidal thoughts. Some victims of bullying have committed suicide. Children as young as nine may think about suicide as a way to escape their bullies [5]. Victims had significantly higher scores on depressive thoughts. Whether bullies, victims, or neutral, girls had significantly higher scores than boys on both suicidal and depressive thoughts [6].

In a study of Lind and Kearney [7]conducted in New Zealand, it turns out that about $63 \%$ of the students have been subjected to some form of bullying practices. Thousands of young people are harassed in schools each day [8]. A study on cyber-bullying in Ireland carried out by O'Moore and Minton [9] comprising 3004 (12-17) year olds (1009 girls, 1995 boys) found that $8.7 \%$ of the Irish teenagers ( $8 \%$ of girls; $9 \%$ of boys) surveyed had cyber bullied others; Minton showed that students who expose to the problems of bullying is primary school students by $35 \%$, and $36.4 \%$ of middle school students. Previous studies has shown that it has major long-and short-term effects on the victim that range from low self-esteem, anxiety, and depression to school a voidance and academic failure [10].

Diligence is some of the underlying psychological mechanisms involve executive control (e.g., planning, keeping track of time, evaluating ideas) [11]. Academic diligence refers to the effort put forth by students to achieve and includes an important group of behaviors (e.g., time spent on homework, task completion, etc.) necessary for students to attain a high level of academic achievement [12].

Research in primary, secondary, and higher education settings has shown that academic diligence may be associated with diverse factors, such as school and its environment, the home and family, students' beliefs and actions [13].

Strategies that address contextual factors in the learning environment and fundamental psychological resources within the student in order to promote academic diligence in schools are: implement school readiness programs that address executive functions, implement interventions that address mindsets, learning strategies, and resilience, consider alternative school models and school-level reform approaches, explore informal learning programs and utilize digital learning environments, online resources, and tools for educators.

School activity is a social phenomenon that affects and affected, positively exercising his noticeable impact on the individual's social, physical and psychological aspects in addition to the achievement of self-satisfaction. The investment leisure time affects the entire educational process, and students who participate in school activities, whether inside or outside the school, often characterized by spirit of leadership, emotional stability, social interaction, and have the ability to persevere when doing their work. The student activity is one of the most important tools that can be used to support normal life of the students, to raise their production and academic achievement.

School activity is an integral part of the educational process, It is an educational program, which resorted to students to achieve certain educational targets inside or outside the classroom, during the school day or after completion of the study that lead to the growth of the student experience and develop hobbies and abilities in educational and social trends desired. In fact, there is considerable evidence that greater learning gains occur when students are placed in diverse, cooperative learning situations with firm guidance and compelling academic content [14]

\section{The Problematic}

What is not discussed often enough is how these acts (participate in bullying-have been bullied) can cause longlasting effects on the school track for students. While talking about the phenomenon of bullying, it is often the focus on the party that it is painful act, which leads to dire consequences on the academic track and mental health, sometimes up to the point of suicide. But if we look at the phenomenon from another way, we will find another victim does not pay attention to it often, it is the students who bully, who want to start the violence and play a leader role, they are victims of the family structure and the social upbringing of children, and both of them need the mental health services. This research will attempt to answer the following questions:

a. What is the prevalence of bullying among high school students?

b. Is there a difference between boys and girls in terms of bullying?

c. Is there a relationship between bullying and diligence at school?

\section{The Aim of the Study}

The present research aims to estimate and compare the prevalence of bullying among high school students, and their relationship with diligence at school. The purpose of this study is to provide concrete, action-oriented information based on the scientific data to help students improve their schools' understanding of and ability to prevent and respond to the problem of bullying.

\section{Study Procedures}

Sample: To achieve the purpose of this research was chosen intended sample selected from High school containing 900 students in Tlemcen -Algeria-, including 406 boys and 496 girls aged between 15 and 17 years old in Algeria, were sampled on the random basis. A research assistant gave questionnaires to students in class and told them that they were not to state their names to ensure anonymity. Approximately 20 minutes was required to 
complete the questionnaire.

Search Tools: Data collection tools were an (School Health Promotion: School efficiency and Bullying) questionnaire containing 105 questions, the purpose of the survey is to gather information about students' experiences of school, their health and their lifestyles. We chose only two variable containing 14 questions. The Arabic form of this questionnaire was adapted from the latest edition created by National Institute for Health and Welfare, School Health Promotion study 2013. PL30 000271. Helsinki [15]. This questionnaire includes answers according to the level of sadness- ranging from 0 to 4 .

It should be noted that SHP questionnaire is a reliable tool approved by National Institute for Health and Welfare. This means proved to be very sensitivity, specificity and efficacy. The validity measurement of the subscale of this test was conducted by (Fekih, 2015) [16], using both methods of reliability and validity tests by re-testing. The results for the validity test were stable. The largest part of the reliability test was connected to bullying ( $89 \%)$. The overall scores must be divided by the number of questions and based on the cutpoint scoring procedure of $6 \%$, which vulnerable conditions will be distinguished.

Statistical methods used in the study: The study on the current descriptive approach, to analyze data from the study, the researcher used a range of statistical methods as the proportions, percentages, Person correlation, (D scale to study the difference between independent proportions).

\section{Procedural Concepts}

Diligence at school: refers to the academic effort put forth by students to achieve and includes an important group of behaviors, was defined as including: efficiency at school, participation in school activities, and resistance to conditions that disturb the work at school, overcome school difficulties and avoid absenteeism.

Bullying: in this questionnaire, bullying refers to the harassment of a pupil by another pupil or a group of pupils either verbally or physically, teasing a pupils repeatedly in ways he or she does not like is also considered bullying, an argument between two roughly equal pupils is not considered bullying.

To determine whether bullying is related to mental health problems at school, students were asked if they bullied at school, they participated in bullying other pupils at school and what did involved?, did the adults in the school intervene in the situation?. Responses were indicated on the same 4point response scale from' not at all' to 'several times a week', and a higher score indicated more mental health problems.

\section{Results}

Table 1. Shows the percentages of both males and females in terms of exposure to harassment or participate in acts of violence inside the school (bulling).

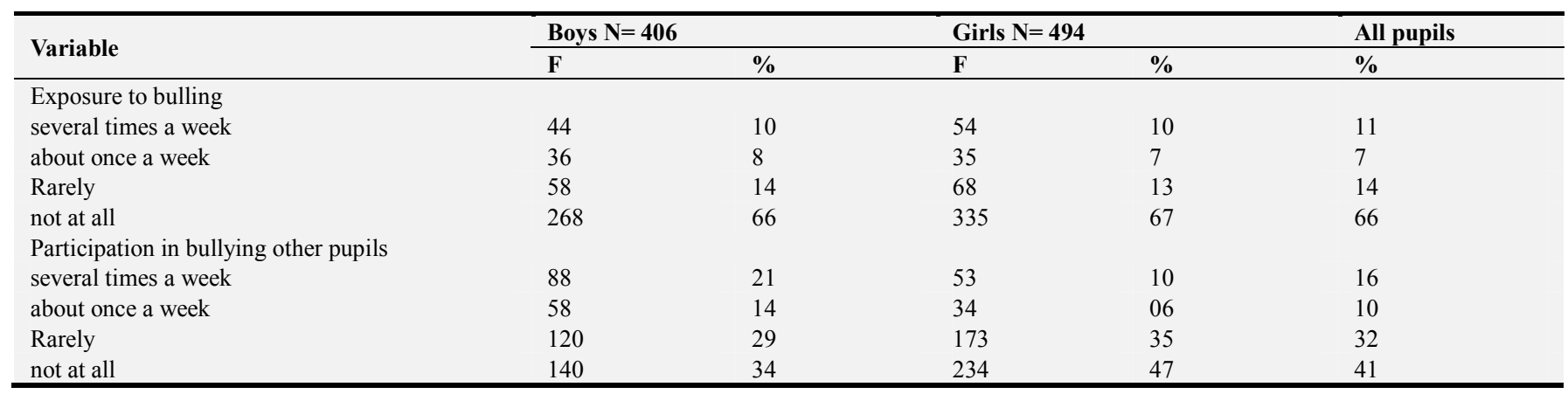

Through Table 1 note that both sexes are being exposure to bulling by the same percentage, while the proportion of male participated in bullying ranging between $14 \%$ and $21 \%$, which is higher than the proportion of females that do not exceed $16 \%$. We also note that the prevalence of bullying inside schools within the limits of $10 \%$ and $16 \%$.

In terms of forms of school violence, whether carried out by the student or exposure to it among students, we observe it in the following table:

Table 2. Shows the percentages of both males and females in terms of forms of violence in schools, whether carried out by the student or exposure to it.

\begin{tabular}{|c|c|c|c|c|}
\hline \multirow{2}{*}{ Variable } & \multicolumn{2}{|c|}{ Boys $N=406$} & \multicolumn{2}{|c|}{ Girls $N=494$} \\
\hline & $\mathbf{F}$ & $\%$ & $\mathbf{F}$ & $\%$ \\
\hline Name-calling, humiliation or offensive teasing & 128 & 31 & 100 & 20 \\
\hline Being ignored or excluded from a circle of friends & 83 & 20 & 68 & 13 \\
\hline Being hit, kicked or shoved & 38 & 9 & 14 & 2 \\
\hline Being told lies about to other pupils/students with intent to hurt & 65 & 16 & 66 & 13 \\
\hline Having money or things stolen, or things broken & 57 & 14 & 41 & 8 \\
\hline Being threatened or forced into doing something you did not want to do & 38 & 9 & 29 & 5 \\
\hline Being abused online or via mobile phone: messages, phone calls, images & 53 & 13 & 50 & 10 \\
\hline Something else & 60 & 14 & 82 & 16 \\
\hline
\end{tabular}


Through Table 2: note that the forms of violence widespread among students is psychological forms of violence as namecalling, humiliation or offensive teasing and being ignored or excluded from a circle of friends.

To compare the difference between the two countries we use the " $\mathrm{D}$ " scale as shown in the following table

Table 3. Shows the results of the D scale to study the difference between independent proportions belonging to the two samples in terms of school violence forms, whether carried out by the student or exposure to it.

\begin{tabular}{|c|c|c|c|c|c|}
\hline$P_{1}$ boys & $P_{2}$ girls & pq & $\mathbf{D}_{\text {calculated }}$ & $\mathbf{D}_{\text {table }}$ & Level of sign 0.05 \\
\hline 0.16 & 0.11 & 0.13 & 05 & 1.96 & Sign \\
\hline
\end{tabular}

Through table 3: we note that there are significant differences between Algerian boys and girls in favor of boys, which means, the boys students in high schools are more violent than girls.

Table 4. Shows the percentages of each of the students in terms of intervention in the school to prevent bullying.

\begin{tabular}{llll}
\hline \multirow{2}{*}{ Variable } & students $\mathbf{N}=\mathbf{5 8 6}$ & \\
\cline { 2 - 3 } & $\mathbf{F}$ (yes) & $\%$ \\
\hline Intervention in the school to prevent bullying & 46 & 7.84 \\
\hline
\end{tabular}

Through Table 4: We note that the intervention of workers to prevent bullying in high schools is very little and insignificant.

Table 5. Pearson Correlation for the relationship between bullying among high school students and their diligence at school $(n=402)$.

\begin{tabular}{llllll}
\hline Bullying & \multicolumn{3}{c}{ Diligence at school } & Pearson Correlation \\
\hline \multicolumn{1}{c}{$\overline{\boldsymbol{x}}$} & $\mathbf{S}$ & $\overline{\boldsymbol{x}}$ & $\mathbf{S}$ & $\begin{array}{l}\text { Level of sign Too tailed } \\
\text { testDf }=\mathbf{4 0 0}\end{array}$ \\
\hline 4,98 & 9,83 & 73,29 & 20,14 & $-0.43^{* *}$ \\
\hline
\end{tabular}

**Correlation is significant at the 0.001 level (2-tailed).

Table 5 shows how bullying is related negatively to diligent at school. Students who were bullied become less efficient, they get low marks, have difficulties in concentration and attention, do not participate in school activities, and absent from school. Such behaviors have a negative impact on mental health inside school, both school administrators, educational staff uniquely affected by these events and feel enormous pressure to help prevent them in the future.

\section{Discussion of Results}

The current study found that the prevalence of bullying among Algerian high school students Almost similar with the prevalence of bullying in Central and Eastern Europe, When results confirm that $35 \%$ of schoolchildren (ages 11-15) said they had been bullied within the past two months, with the percentage ranging from $15 \%$ in Sweden to $64 \%$ in Lithuania". In countries such as Greece the percentage of children that said that they had been bullied within the last two months was $23 \%$ in females and $26 \%$ in males, in USA $33 \%$ in females and $36 \%$ in males, in the UK $32 \%$ in females and $32 \%$ in males and in France $36 \%$ in females and $34 \%$ in males [17].

The policy followed by Finland are effective in the fight of bullying in schools, When the study of Kaltiala-Heino [18] confirms that In Finland, from a sample of 8th and 9th graders (ages 14-16 years), 11\% reported bullying others at least once weekly and $11 \%$ reported being bullied at least once weekly.

All studies confirm that bullying can cause problems at school. A lot of secondary school children are bullied at some point; many of them are bullied every week, for that, violence becoming part of the daily life of our schools. It refers to behavior resulting from intention, real or imagined, to hurt another person physically, materially, symbolically, etc. As for bullying, one of the main types of violence in schools, it can be direct (physical or verbal aggression) or indirect (social or relational aggression) [19].

It differs from the violence taken in its context in three main ways: the actions are taken over a long period of time; they are committed repeatedly; the balance of power is unequal (domination relationship).

For both the bully and the student who is bullied, the cycle of violence and intimidation results in greater interpersonal difficulties and poor performance in school. Students who are bullied are more likely than their peers to be depressed, lonely, or anxious and have low self-esteem. Bullies often act aggressively out of frustration, humiliation, anger and in response to social ridicule.

The current study also found that bullying is related negatively to diligent at school. For both the bully and the student who is bullied, the cycle of violence and intimidation results in greater interpersonal difficulties and poor performance in school. These results are consistent with research showing a negative effect on students who are bullied at school [20]. Students who are bullied are more likely than their peers to be depressed, lonely, or anxious and have low self-esteem. Bullies often act aggressively out of frustration, humiliation, anger and in response to social ridicule.

The school as an institution includes students, teachers, administrators, school space and the interaction between these categories through daily communication, within this institution stands out extensive social relations among its members, and that the nature of the contact, whether 
functional or non-functional have a great impact on academic achievement [21]. In fact there is no difference between education and mental health, the difference between them is in titles, mental health is the ability to overcoming the stress, endure hardship, confrontation and maintain personal balance during crisis situations. So education is a continuous process aimed at individual success in educational institutions, normal growth personally cognitively and socially. Among the most important success factors focus on the role of the teacher, through effective training programs before and during the service, to prepare him to deal with the psychological problems of the students in their early stages. This is done through the promotion of mental health services in school.

Recent studies have pointed the importance of psychological aspects in school achievement, from these aspects we have adaptation of student in school, and these studies have shown that outstanding students are characterized by a high level of psychological and social security, and are characterized by normal self-confidence and social adjustment with others [22].

The school is not only a place where students are all to gather to get educational attainment, it is a small community interact in it where some of them interconnected with each others, they feel affiliation, and care about the common objectives for their school. All of this leads to the creation of the school spirit among them, and the appropriate atmosphere to the individual and social development [23].

The students like other members of community, they have motives, physical, psychological and social needs which seek to satisfy it, and the extent of adaptation depends on degree of this satisfaction. Children who struggle socially or emotionally are less likely to benefit from academic instruction [23]. So the school must take its role in helping them to reach a better level of social adjustment, and not being able to satisfy these needs lead to negative results, the most important reason of their failure is maladjustment to school life.

Therefore, the fundamental factors that check the personal, environmental and social adjustment to student are characteristics and advantages of the student's personality such as health, sex, age, level of education, temperamental traits, personal habits, level of ambition, socialization and the experience acquired through belonging to multiple groups [24].

The relationship of Student with each other's is one of public relations in the school environment, may have a peer group influence on student behavior more than the family, teachers, educators and others affect, so that the student while joining these groups it shares with its members the interests and ideas, and check him certain interests [25]. Cooperation involves much more than being physically near other students, discussing material, helping, or sharing material with other students. There is a crucial difference between simply putting students into groups to learn and in structuring cooperative interdependence among students [26]. The group field welcomed the friendship and fellowship in which the student feels to physical integrity, and the importance of social status, he sympathizes with others and sympathetic to others with him, as it finds it offers him advice and guidance and guided to avoid mistakes, and that the group is a source of information that he wants to know. Community In addition to the above, give to student desire to compete or cooperate and give it the opportunity to prove his abilities and energies running and gets the respect of others [27].

The victim of bullying is defenseless against her attacker, which is not necessarily the case when it comes to violence. The consequences of violence and bullying on school climate and success are diverse (peer rejection, truancy, school failure, etc.). Prevention and fight against violence and intimidation must be part of a commitment of all stakeholders' school environments to support the creation of safe educational environment and support the development of students.

\section{References}

[1] Centers for Disease Control and Prevention. Youth risk behavior surveillance. United States, 2011. MMWR.

[2] Keith, S., Mark, C., Gunny, S. (2005). Bullying in secondary schools (2nd ed.). London: PCP. Corwin press.

[3] Dan, O. (1993), Bullying at School: What we know and what we can do. (Oxford, England): Blackwell Publishing.

[4] Juvonen, J., Graham, S. (2014). Bullying in schools: The power of bullies and the plight of victims. Annual Review of Psychology (Annual Reviews), 65: 159-85.

[5] Van der Wal, M. F., de Wit, C. A. M., \& Hirasing, R. A. (2003). Psychosocial health among young victims and offenders of direct and indirect bullying. Pediatrics, 111, $1312-1317$

[6] Erling, R. (2002). Bullying, depressive symptoms and suicidal thoughts. Educational Research, V44, (1), 55-67.

[7] Lind, J. C, Kearney, A. (2004). Bullying: What do students say?. Massey University College of Education, Kairaranga, V $5,(2), 19-24$.

[8] O'Hanlon, L. H. (2006, October). Hostile halls. Current Health 2, 33(2), 16-18.

[9] O'Moore, A. M, Minton, S. J. (2009). Cyber-Bulling: The Irish experience in, editor(s) Quinn, Q \& Tawse, S., Hand Book of Aggressive Behavior Research, Hauppauge, NY, Nova science publishers, Inc.

[10] Swearer, S. M., Song, S. Y., Cary, P. T., Eagle, J. W., Mickelson, W. T. (2001). Psychosocial correlates in bullying and victimization: The relationship between depression, anxiety, and bully/victim status. Journal of Emotional Abuse, 2(2/3), 95-121.

[11] Diamond, A., Lee, K. (2011). Interventions shown to Aid Executive Function Development in Children 4-12 Years Old. Science. 19: 333 (6045): 959-964.

[12] Duckworth, A. L., Peterson, C., Matthews, M., \& Kelly, D. (2007). Grit: Perseverance and Passion for Long-Term Goals. Journal of Personality and Social Psychology, 92, 1087 - 1101. 
[13] Shechtman, N., DeBarger, A., Dornsife, C., Rosier, S., Yarnall, L. (2013). Promoting grit, tenacity, and perseverance: Critical factors for success in the 21st century. Washington, DC: US Department of Education, Department of Educational Technology (pp. 1-107). San Francisco, CA.

[14] Slavin, R. (1990). Cooperative learning: Theory, research, and practice. Englewood Cliffs, NJ: Prentice Hal.

[15] School Health Promotion study 2013. PL 30 000271. Helsinki.

[16] Fekih, L. (2015). The validity of School Health Promotion scale, Journal of Psychometric Studies, PNR, Algeria, the first issue, May 2015.105-138 (In Arabic).

[17] Currie C et al (eds.) (2004) Young People's Health in Context: international report from the HBSC 2001/02 survey, (Health Policy for Children and Adolescents, No. 4). WHO Regional Office for Europe, Copenhagen.

[18] Kaltiala-Heino, R., Rimpela, M., Marttunen, M., Rimpela, A., Rantanen, P. (1999). Bullying, depression, and suicidal ideation in Finnish adolescents: School survey, British Medical Journal, 319, 348-351.

[19] Straus, M. A., \& Gelles, J. (1990). Physical violence in American families. Risk, factors and adaptations to violence in 8,145 families. New Brunswick, New Jersey: Transaction publishers.

[20] Tanya, B., Qing, L. (2007). The Relationship between cyberbullying and School Bullying. Journal of Student Wellbeing. V. 1(2), 15-33.
[21] Eyler, J., Giles, D. (1999). Where's the learning in servicelearning? Jossey-Bass, San Francisco.

[22] Brown, J. D., Riley, A. W., Wissow, L. W. (2007). Identification of youth psychosocial problems during pediatric primary care visits. Administrative Policy on Mental Health and Mental Health Services Research, 34, 269-281.

[23] Brener, N. D., Weist, M. Adelman, H., Taylor, L., VernonSmiley, M. (2007). Mental health and social services: Results from the school health policies and programs study 2006. Journal of School Health, 77, 486-499.

[24] Wang, M. C., Haertel, G. D., Walberg, H. J. (1998). Building educational resilience. Bloomington, Indiana: Phi Delta Kappa Educational Foundation.

[25] McCaslin, M., Good, Tom, L. (1996). The informal curriculum. In The Handbook of Educational Psychology, ed. David C. Berliner and Robert C. Calfee. New York: American Psychological Association/Macmillan.

[26] Smith, K. A. (1996). Cooperative learning: Making "group work" work. In C. Bonwell \& T. Sutherlund, Eds., Active learning: Lessons from practice and emerging issues. New Directions for Teaching and Learning, 67, 71-82. San Francisco: Jossey-Bass.

[27] Cangelosi, J. S. (1993). Classroom Management Strategies: Gaining and Maintaining Students' Cooperation. White Plains, NY: Longman. 